\title{
Update on the Epidemiology of Melanoma
}

\author{
Steven T. Chen, MD MPH ${ }^{1}$, Alan C. Geller, MPH RN ${ }^{2}$, and Hensin Tsao, MD PhD ${ }^{1}$ \\ ${ }^{1}$ Department of Dermatology, Massachusetts General Hospital, Harvard Medical School, Boston, \\ MA \\ ${ }^{2}$ Department of Society, Human Development, and Health, Harvard School of Public Health, \\ Boston, MA
}

\begin{abstract}
Cutaneous malignant melanoma (CMM) has been increasing steadily in incidence over the past 30 years. Recent studies have explored associations between CMM and varying physiologic risk factors, such as nevi or hair and eye color, in addition to historical features such as a personal history of nonmelanoma skin cancer (NMSC), childhood cancers, Parkinson's Disease, hormone exposure and family history of CMM. Genome-wide association studies have also uncovered many genetic determinants of CMM risk. Ultimately, ultraviolet (UV) radiation exposure remains the most important modifiable risk factor for CMM. Organ transplant recipients, and nonsteroidal anti-inflammatory usage may also play a role. While risk factors are important to identify, effective campaigns to reduce the burden of disease through early detection and prevention are essential. We present detailed data regarding these facets of care for the CMM patient, and provide an update on the epidemiology of CMM.
\end{abstract}

\section{Keywords}

Melanoma; Epidemiology; Genetics; Cancer

\section{INTRODUCTION AND TRENDS IN MELANOMA}

In 2012, 9180 individuals are estimated to die from melanoma in the United States.[1] As the most lethal form of skin cancer,[2] the increasing incidence of cutaneous malignant melanoma (CMM) is an increasing burden to society.[3] As the fifth most common malignancy in men, and sixth most common in women, CMM is expected to account for less than 5\% of all skin cancer diagnoses, but will account for the vast majority of skin cancer deaths. That said, when compared with all cancers, it remains as one with a relatively high 5-year survival. Only prostate, thyroid, and testis cancer have better 5-year survival rates, while melanoma has a higher 5-year survival rate than 14 other malignancies reviewed.[1]

Corresponding Author: Hensin Tsao, MD PhD, Bartlett Hall, $6^{\text {th }}$ floor, Massachusetts General Hospital, 55 Fruit Street, Boston, MA 02114, htsao@partners.org, Fax: 617-724-2745.

Author information:

Steven T. Chen, MD MPH, Bartlett Hall, $6^{\text {th }}$ floor, Massachusetts General Hospital, 55 Fruit Street, Boston, MA 02114, stchen@ partners.org, Fax: 617-724-2745

Alan C. Geller, MPH RN, Kresge Building, Room 701A, 677 Huntington Avenue, Boston, Massachusetts 02115, ageller@hsph.harvard.edu

Disclosure

ST Chen and AC Geller reported no potential conflicts of interest relevant to this article; H Tsao is a Board Member with Journal Watch and the British Journal of Dermatology, is a consultant with Scibase, Quest, WorldCare Clinical, Genentech, and has received royalties from Journal Watch Dermatology. 
The incidence of melanoma is growing more rapidly than nearly all other cancers in the US. [3] In 2012, there will be an estimated 76,250 new cases of melanoma.[1] The incidence has been increasing steadily for the past 30 years, and since 2004, Caucasians have seen a 3\% increase each year.[1] A review of the Surveillance, Evaluation, and End Results (SEER) data found a similar increase in incidence to be further accentuated among young Americans, particularly amongst females aged 15-39.[4] A recent review of the population in Olmsted County, Minnesota found a similar increase among young women aged 18-39, who saw an 8-fold increase compared to the 4-fold increase in young men.[5] However, this trend is extinguished among women after the age of forty, while incidence increases dramatically in men after this age.[6] Aside from behavioral factors (e.g. sun lamp use), hormonal influences have been posited to play a role in this finding. $[5,6]$ However, what is increasingly obvious is the complexity and heterogeneity of melanoma. Studies have also shown age-specific effect modification for gender, anatomic site, and histopathology.[6]

Importantly, melanoma survival has steadily improved over the past few decades. 5-year survival has increased from $82 \%$ to $91 \%$ between 1979 and 2012.[1] Arguably, the most important prognostic factor at time of CMM diagnosis remains tumor thickness, which unfortunately has not decreased in recent studies. The study from Olmsted County found that with time, there was a decrease in the level of invasion and stage of disease at time of diagnosis.[5] While some may argue the undue influence of overdiagnosis of early lesions, the proportion of thick melanomas has remained relatively constant and it is possible that lesions are being identified early at a thin enough stage to be truly cured with surgical excision.[6]

With the advent of newer therapeutic options such as immunotherapies and targeted molecular therapies, progression-free survival has already been shown to improve while the hope is that overall survival will also soon follow. Both ipilimumab and vemurafenib have been investigated against dacarbazine, and have been found to increase overall survival in metastatic melanoma.[7] Despite new developments in therapy, early detection and prevention will be key factors in reducing the burden of CMM.

\section{Economic considerations}

While the burden of the loss of human life is one that is obvious, another burden that cannot be ignored is the economic cost of melanoma to the US healthcare system. Unlike other malignancy diagnoses, the cost of melanoma is not as high at time of diagnosis, largely due to the outpatient nature of follow up appointments and procedures.[8] However, when the cost of melanoma is focused on the period of time designated as the terminal phase (6 months prior to death), the cost of healthcare for the melanoma patient skyrockets and has been reported to cost as much as the cost for the care of a colorectal cancer patient.[8] Indeed, prior studies have quoted the cost spent during this 6-month terminal period to account for $90 \%$ of the healthcare cost for any particular patient.[9] Undoubtedly, the cost of melanoma care will further increase with the use of newer targeted agents, not only because of drug charges, but also because of the management of complications and side effects now reported with these new treatment modalities (e.g. keratoacanthoma-like squamous cell carcinomas).[10]

Given the high cost that goes toward the care of the patient with advanced melanoma, it would stand to reason that early detection and prevention could be more cost effective, however studies on the financial ramifications have not yet been instructive in this regard. 


\section{RISK FACTORS}

While a discussion of risk factors for CMM is important, it is also critical to differentiate behavioral versus heritable factors. Clearly, there are complex interactions between the environment and genetics. We will begin our review of risk factors with those that are known physiologic risk factors.

\section{Known phenotypic risk factors}

Nevi-A meta-analysis published in 2005 investigated the increased risk of CMM given a particular patient's propensity to develop nevi, both common and atypical.[11] Case-control, cohort, and cross-sectional studies were included and reviewed. For common nevi, the metaanalysis found that the number a patient has is a risk factor for developing CMM. A dose response pattern was seen with an increase in relative risk (RR) for developing CMM as a patient's number of common nevi increased.[11] When those with 0-15 common nevi on the entire body were treated as baseline, the RR was reported to be $1.47(1.36,1.59)$ for patients with 16-40 common nevi, $2.24(1.90,2.64)$ for $41-60$ common nevi, $3.26(2.55,4.15)$ for $61-80$ nevi, $4.74(3.44,6.53)$ for $81-100$ nevi, and finally $6.89(4.63,10.25)$ for patient with 101-120 common nevi.[11] When common nevi were only counted on arms, patients with $1-5$ common nevi showed a RR of $1.44(1.29,1.60)$ when compared to those without any nevi on the arms. The same dose response curve was exhibited when those with 5-10 common nevi on the arms showed a RR of $2.48(1.90,3.23)$, and those with 11-15 nevi had a RR of $4.82(3.05,7.62)$.[11]

When analyzing atypical nevi, a similar density-risk-curve was demonstrated. Patients with a history of one atypical nevus showed a RR for developing CMM of $1.45(1.31,1.60)$ when compared with those with no atypical nevi. Patients with two atypical nevi showed a RR of $2.10(1.71,2.54)$, with three a RR of $3.03(2.23,4.06)$, with four a RR of $4.39(2.91,6.47)$, and finally with five a RR of $6.36(3.80,10.33)$.[11]

A more recent meta-analysis performed in 2010 found that having more than 25 nevi may also be a risk factor for CMM diagnosis.[12] In this particular study, 42 percent of CMM cases were associated with having over 25 nevi, with a population attributable fraction of 0.15.[12] Unfortunately, as this was a meta-analysis, the studies did not uniformly perform subgroup analyses by age, gender, skin type. Therefore, it is difficult to make conclusions about these subgroups.

Hair and Eye Color-A similar meta-analysis by the same group evaluated 37 studies that reported eye color and risk of melanoma.[13] Comparisons were made between different eye color groups and the "dark" eye color group. Blue eye color was found to have a RR of 1.47 $(1.28,1.69)$ when compared with dark eye color for melanoma. For green eye color, the RR was reported as $1.61(1.06,2.45)$. Finally, for hazel, the RR was reported as $1.52(1.26$, 1.83). When all groups were combined as "fair eye color," the RR for melanoma was 1.62 $(1.44,1.81)$ when compared with "dark eye color.”[13]

As for hair color, 45 studies were reviewed and similarly to eye color, different hair colors were compared to "dark hair color" for RR for melanoma.[13] Red hair was found to have a RR of 3.64 (2.56, 5.37), blond hair a RR of $1.96(1.41,2.74)$, and light brown a RR of 1.62 $(1.11,2.34)$. When the blond, red, and light brown hair groups were collapsed into "light" hair color and compared with the "Medium dark, brown" group, the RR of melanoma was $1.78(1.63,1.95)$.

Family History-A meta-analysis of 14 individual case-control studies evaluating the association of family history (defined as a first degree relative with the diagnosis of CMM) 
was performed. Those with a positive family history, when compared to those without, had a RR of 1.74 (1.41, 2.14) for developing CMM.[13]

Personal History of Non-melanoma Skin Cancer-There have been multiple publications that explore the risk of malignancy after having a diagnosis of non-melanoma skin cancer (NMSC). One systematic review explored the possible associations, and cited both anecdotal evidence that those with NMSC seem to have an increased risk of other malignancies, as well as the conjecture that those with NMSC history may have higher levels of vitamin D secondary to sun exposure, perhaps eliciting a protective effect.[14] When dealing with the possible association with development of CMM, one would expect to see a positive association given the similar risk factors, namely fair skin and excessive sun exposure. Indeed, that is what was seen with a summary RR of $2.74(2.49,3.02)$ for developing CMM in the NMSC population when compared with controls without a history of NMSC.[14] When further subdivided into type of NMSC, there was no large difference seen. In those with history of squamous cell carcinoma (SCC), the RR of CMM diagnosis was 2.84 (2.45, 3.29); for basal cell carcinoma (BCC) the RR was reported as 2.75 (2.39, 3.16). Similarly, the RR of CMM diagnosis after NMSC was similar across genders. In males, the RR was 2.73 (2.52, 2.96), and in females, RR was 2.61 (2.24, 3.05).[14] It is worth noting that patients with NMSC may be scrutinized to a greater extent and therefore the apparent elevations in risk could result from a detection bias.

Childhood cancer history-Having a history of cancer in childhood is a risk factor for subsequent malignancy.[15] Prior studies have reported the overall increased risk of subsequent malignancy to be six-fold. When a group of childhood cancer survivors were reviewed for subsequent CMM risk, the standardized incidence ratio (SIR) was found to be $2.42(1.77,3.23)$.[15] The childhood cancer cases that preceded CMM diagnosis included soft tissue and bone sarcoma, leukemia, lymphoma, central nervous system malignancy, Wilm's tumor, and neuroblastoma.[15]

Parkinson's Disease_A large systematic meta-analysis published in early 2010 reviewed the associations of Parkinson's Disease (PD) with various malignancies.[16] Among the reported malignancies was CMM, which showed that after evaluation of eight studies (which was unfortunately a small portion of available literature), the RR for patients with PD for the development of CMM was 1.56 (1.27, 1.91).[16] Interestingly, melanoma was the only malignancy reviewed with an increased RR. In fact, overall, PD was found to be protective with a decrease of 27 percent in the risk of cancer.[16] When CMM was taken out of the analysis, the protective effect increased to a 38 percent difference. It seems that $\mathrm{PD}$ is a unique risk factor for CMM, as opposed to a protective factor for other malignancies studied. That said, many studies have posed that perhaps the relationship between CMM and PD may be in the opposite direction, or perhaps it is a bidirectional relationship.

This association was further explored in a study published in the neurology literature one year later.[17] 14 papers were identified, with 13 used for analysis. This study reports on the possible association between the two entities and attempts to explore the directionality of the association by subdividing the papers by temporal association.[17] Overall, the odds ratio (OR) for association of PD and CMM was reported as $2.11(1.26,3.54)$.[17] When the papers were subdivided by temporal relationship, the statistically significant relationship was reported in cases where PD preceded CMM, where OR was $3.61(1.49,8.77)$. On the other hand, if CMM preceded PD, the OR was reported as $1.07(0.62,1.84)$.[17] The authors pose that this loss of statistical significance is due to one study and, when removed, the OR increased to $1.44(1.06,1.96)$. While it may be tempting to try to make inferences about possible causation, one should be careful in assuming this type of relationship as many of these studies are case-control studies, limiting our ability to infer a causal relationship. 
When the group was stratified by gender, statistical significance was seen in men, where the OR of the association was reported as $2.04(1.55,2.69)$. However, there was a lack of statistical significance in women, where the OR was $1.52(0.85,2.75)$.[17]

The evidence for the association of CMM with PD is less convincing. One concern regarding this potential relationship relates to the population that is most at risk for PD. As hair color has been associated with variable risks for PD, one could argue that perhaps the association of PD and CMM may actually be confounded by ethnicity.[18] Although speculative, the substantia nigra, which undergoes attrition in PD, is composed of highly melanized dopaminergic neurons and thus deficiencies in eumelanization or increases in pheomelanin may account for the predisposition to both melanoma and PD. As such, future studies will need larger sample sizes, more carefully designed and defined prospective designs, possibly culminating in more sophisticated meta-analyses.

Pregnancy and Hormones-A systematic review by the Gandini group sought to explore the possible association of hormonal factors with CMM, given the many case studies and anecdotal reports of CMM in the setting of pregnancy.[19] 36 publications were reviewed to explore this possible association. Given the conjectured mechanism through hormonal mediators, the systematic review analyzed research that sought to find associations between either hormone replacement therapy (HRT) or oral contraceptives (OC) with CMM. When pooled, the RR for those on OC for development of CMM was a RR of $1.04(0.92,1.18)$. For HRT, the RR was $1.16(0.93,1.44)$. The lack of statistical significant was similarly seen despite subgroup analysis of different time courses of these therapies.[19] This corroborates evidence published earlier regarding the lack of association between OC use and CMM.[20]

There has also been no detectable association between CMM and other reproductive factors (eg: age at menarche, evaluation of fertility, use of fertility drugs, parity, menopausal status, or age at menopause). There was a small statistically significant association of an increased $10 \%$ risk found for women whose first pregnancy was at the age of 30 or higher, when compared to those whose first pregnancy was at age 20 or younger.[19] This association however, was found to have been possibly confounded by socio-economic status (SES).[19]

Vitamin D-Multiple case control studies from the UK have explored the possible association of vitamin D receptor (VDR) single nucleotide polymorphisms (SNPs) with CMM. Out of six potential VDR SNPs under investigation, one in particular showed a positive association with CMM after meta-analysis.[21] The T allele of the FokI polymorphism showed an OR of $1.19(1.05,1.35)$ for CMM. Conversely, a different VDR SNP was found to possibly be protective. The BsmI A allele was found to have an OR of $0.81(0.72,0.92)$ for CMM.[21]

Mechanistically, the $\mathrm{T}$ allele of the FokI gene is known to produce an alternative start site at the $5^{\prime}$ end, which leads to a protein that is 3 amino acids longer (427 aa) than the wild type protein (424 aa). In vitro studies have found a less efficient interaction with certain transcription factors with the mutant 427 amino acid protein[21] and could help explain why this T-allele of FokI is also associated with colon and breast cancers.[21]

Notably, in terms of vitamin D intake, a recent study in 2009 reviewed data from the SEER database which compared CMM diagnosis between the population in the top quartile of vitamin D intake and the population in the bottom quartile of vitamin D intake. This study did not show any association between CMM risk and vitamin D intake.[22] 


\section{Recently Uncovered Genetic Factors}

High risk loci-Suspicion for a hereditary cause of melanoma arises in three main situations: when CMM diagnosis occurs at an early age, when there are multiple diagnoses of CMM on one side of the family, or when an individual has multiple diagnoses of primary CMM.[23] In Familial atypical multiple mole-melanoma (FAMMM) syndrome, patients are identified based on diagnosis of melanoma, as well numerous atypical appearing nevi.[23] Based on linkage analysis performed on patients and families with this phenotype, germline mutation in $C D K N 2 A$ were first identified in the context of hereditary melanoma.[23]

This gene can code for two distinct proteins through alternative splicing mechanisms. The $C D K N 2 A$ locus includes four exons, which code for either p16/Ink4, or p14/Arf. Both products function as potent tumor supressors, which when mutated, enable uncontrolled cell division and tumor development. p16/Ink4 in particular, when mutated, has also been associated with pancreatic cancer. When p16/Ink4 is wildtype and fully functional, it binds $\mathrm{Cdk} 4$ and prevents it from phosphorylating Retinoblastoma $(\mathrm{Rb})$, another tumor suppressor. [23] A heavily phosphorylated $\mathrm{Rb}$ will release E2F1, a transcription factor responsible for switching on the synthesis of S phase genes.[23] As such, a mutated p16/Ink4 (which would dis-inhibit Cdk4), or a mutation in Cdk4 (leading to a p16-resistant protein) both can lead to similar phenotypes, as these mutations hyperphosphorylate Rb, leading to release of E2F1 and subsequent transition of cells from G1 arrest into the S phase.[23] There have been two reported mutations discovered in the $C D K 4$ gene, whereas a whole host of mutations have been described in $C D K N 2 A$.[23] The penetrance of these mutations in $C D K N 2 A$ is variable, and was when investigated within high risk families, it was reported to be $30 \%$ at age 50 , and $67 \%$ at age 80 globally.[23] When subdivided by region, the variability was further elucidated, with $13 \%, 50 \%$, and $32 \%$ at age 50 for Europe, the United States, and Australia respectively. At age 80, the penetrance was $58 \%, 76 \%$, and $91 \%$ for Europe, the United States, and Australia respectively.[23] However, when penetrance was ascertained through the melanoma population in general, it was reported as $14 \%, 24 \%$, and $28 \%$ at ages 50,70 , and 80 respectively.[23] This disparity speaks to the possible influence of co-inherited modifiers in families and also to the contribution of ambient sunlight in modulating overall risk among carriers.

CMM is not limited to the cutaneous surface, but can also affect other organs. Ocular melanoma (OM) in particular has been noted to run in families, and a mutation in BRCAassociated protein 1 (BAP1) was found to occur in a large proportion of OM that also exhibited monosomy 3.[24] This mutation does not occur in OM in isolation, but it has also been noted in families with multiple kindreds with cases of both OM and cutaneous CMM. [24] A recent study found that BAP1 was seen at a higher frequency in patients with metastatic OM when compared with controls with nonmetastatic OM.[24] BAP1 was also found to occur at higher frequency in families with both cutaneous CMM and OM.[24] As such, BAP1 has been identified as the mutation with a newly named COMMON syndrome (Cutaneous and Ocular Melanomas, Melanocytic proliferations, and Other Neoplasms).[24] While the other neoplasms are not completely elucidated, the study families did include three patients with lung cancer, two of which had the BAP1 mutation. Also, BAP1 has emerged as a target for both somatic and germline mutations in mesothelioma.[24]

Low to Moderate Risk Alleles-Melanocortin-1-receptor (Mc1r) variants have previously been reported to be associated with CMM.[25] Phenotypically, it has been associated with the "red hair color" (RHC) phenotype.[25] When Mc1r is in its wild-type form, it binds alpha-melanocyte stimulating hormone (aMSH), which induces cAMP thereby triggering the production of eumelanin. However, Mc1r variants do not respond properly to aMSH and therefore pheomelanin accumulates.[25] A review from 2008 
performed a meta-analysis on the nine most common variants in $M C 1 R$. Based on pooled results, authors identified multiple genetic variants of $M C 1 R$ that were associated with development of melanoma, as well as RHC.[25] These included p.D84E, p.R142H, p.R151C, p.R160W and p.D294H. Notably, the first two of these variants (p.D84E and p.R142H) were previously reported to not be associated with CMM and may have only surfaced given the aggregate power of the meta-analysis,[25-28] The authors also report an association found for variants p.I155T and p.R163Q with CMM, however not with RHC, arguing that certain $M C 1 R$ variants can increase risk of CMM outside of the pigmentary pathways.[25] Another meta-analysis of the same 9 variants was published in 2011. In this study, the genetic variations were divided into those that were and those that were not associated with the RHC phenotype (non RHC, or NRHC).[29] When pooled, those variants that are also in the RHC phenotype group increased the patient's RR for CMM to 2.44 (1.72, $3.45)$ when compared to individuals with wild-type Mc1r. There was a more modest increase in risk in the NRHC cohort with a RR for CMM of 1.29 (1.10, 1.51).[29] While the Raimondi et al article from 2008 did not find an increased association for the pV60L nor $\mathrm{pV} 92 \mathrm{M}$ alterations, these two variants were indeed found to have significantly significant increased ORs in the 2011 meta-analysis.[25, 29]

While those patients with a $C D K N 2 A$ mutation may unfortunately be at great risk given the relatively high penetrance of those genetic mutations, Mc1r variants confer a lower risk[30]; the estimated OR of developing melanoma among carriers of Mc1r variants compared to wildtype individuals is 2.2 to 3.9. [31] What is interesting is the interplay between these two genes. When the MC1R variant is present, the penetrance of $C D K N 2 A$ mutation increases, in some reports as much as by 34 percent.[32] Also, those families with a known $C D K N 2 A$ mutation also see a doubling of risk of CMM with the presence of an MC1R variant.[33]

Genome Wide Association Studies-With the advent of newer and more easily accessible technology, there have been many new reports of potential genetic associations with CMM, largely through the use of genome wide association studies (GWAS). This is in large part an effort to help explain the "missing heritability" of common diseases.[6]

A GWAS from 2008 reviewing records from 2019 cases and 2105 controls found a new risk locus on chromosome 20 (20q11.22) and two single nucleotide polymorphisms (SNPs) (rs910873 and rs1885120) that are $1.5 \mathrm{Mb}$ apart with a combined $\mathrm{P}<1 \times 10^{-15}$.[34] A year later, a group reported a newly discovered SNP associated with CMM through GWAS performed on 1650 cases and 4336 controls. Five loci with SNPs reaching statistical significance were discovered, three of which were validated in two replication cohorts. rs 258322 at $16 \mathrm{q} 24$ on the MC1R gene $\left(\mathrm{P}=2.54 \times 10^{-27}\right)$, rs1393350 at $11 \mathrm{q} 14-\mathrm{q} 21$ at the tyrosinase $(T Y R)$ gene $\left(\mathrm{P}=2.41 \times 10^{-14}\right)$, and rs 7023329 at $9 \mathrm{p} 21$, adjacent to MTAP and flanking $C D K N 2 A\left(\mathrm{P}=4.03 \times 10^{-7}\right)$.[35]

Two other studies in 2009 sought to link the SNPs associated with certain phenotypic characteristics with CMM. Three SNPs (rs28777, rs35391, and rs16891982) in the MATP gene locus (which mediates melanin synthesis and pigmentation) were associated with CMM, however this association was attenuated when ancestry was controlled.[36] A separate study sought to link SNPs with one of the known risk factors for CMM, a high melanocytic nevi count.[37] In this study, using 1524 healthy female twins, and 297,108 candidate SNPs ( $>1 \%$ minor allele frequency), the authors identified 12 SNPs that clustered to the $9 \mathrm{p} 21$ or $22 \mathrm{q} 13$ loci. These SNP associations were validated on a separate twin database. The strongest association was found with rs4636294 (combined $\mathrm{P}=3.4 \times 10^{-15}$ ), which maps to the MTAP gene at 9p21, next to CDKN2A.[37] The other SNP (rs2284063) which mapped to $22 \mathrm{q} 13 \mathrm{had}$ a $\mathrm{P}$ value of $3.4 \times 10^{-8}$.[37] By using these new candidate SNPs, the authors were able to explore the joint ORs of these SNPs in association with other 
previously described SNPs in the same loci.[37] At 9p21, rs10757257 with rs4636294 demonstrated a joint $\mathrm{OR}$ of $1.21(1.14,1.28)$ with a $\mathrm{P}=3.7 \times 10^{-8}$.[37] For 22q13, rs132985 with rs2284063 had a joint OR of $1.19\left(1.12,1.27, \mathrm{P}=1.5 \times 10^{-6}\right)$.[37] As such, the authors were able to demonstrate that not only are these SNPs associated with this particular phenotype of multiple melanocytic nevi, but also able to show linkage with CMM.[37] Another study that sought to do the same analysis for SNPs associated with high melanocytic nevi count used an Australian twin database and identified multiple SNPs associated with the Interferon regulatory factor-4 (IRF4) gene.[38] rs12203592 was associated with high freckling in both adolescents and adults, however only high nevus counts in adolescents. This SNP when investigated from melanoma case-control studies from Australia, the UK, and Sweden was found to have an increased OR for CMM at 1.15 $(1.046,1.264) .[38]$ Most recently, an article from 2011 reported rs 12913832 (in conjunction with rs1129038), which mapped to 15q13.1 and has a profound association with eye and skin color.[39]

On the other hand, other studies have found SNPs that do not seem to be associated with any phenotypic features. In 2011, Barrett et al demonstrated rs 1801516 that mapped to the $A T M$ gene $\left(\mathrm{P}=3.4 \times 10^{-9}\right)$, rs 13016963 adjacent to $C A S P 8\left(\mathrm{P}=8.6 \times 10^{-10}\right.$, and rs45430 at the $M X 2$ locus $\left(\mathrm{P}=2.9 \times 10^{-9}\right)$.[40] MacGregor et al reported on rs7412746 at $1 \mathrm{q} 21.3(\mathrm{P}=9.0 \times$ $\left.10^{-11}\right)$, as well as rs3219090 at $1 \mathrm{q} 42.12\left(\mathrm{P}=9.3 \times 10^{-8}\right)$, which corresponds to candidate loci $A R N T$ and SETDB1, respectively.[41] These SNPs were not found to be associated with any phenotypic variant, such as high density of nevi.[41]

Finally, this year, an article has also explored the opposite: a protective effect of a SNP on CMM. At 5p15.33, rs401681 was previously reported as demonstrating a lower OR with CMM, however in this study, two other SNPs were also identified in the same locus of the TERT-CLPTM1L. rs13356727 and rs4975616 were explored alongside rs401681, and when each SNP was covaried by the other two, on rs 13356727 remained statistically significant, signifying that perhaps, this is the best marker for the protective effects at this locus.[42] The mechanism of this action is posed as a possible protective effect against excessive melanocytic nevi count.[42]

\section{Known Exogenous or latrogenic Factors}

Sun Exposure-Exposure to UV radiation through sun exposure is arguably the most easily modified risk factor for CMM. Numerous studies published have linked sun exposure to the risk of CMM diagnosis. A recent meta-analysis in 2005 reviewed 57 studies published prior to 2002 found that both intermittent sun exposure and sunburn history played a crucial role as a risk factor for the development of CMM.[43] The relative risk for "Total Sun Exposure" and resultant melanoma diagnosis was reported to be $1.34(1.02,1.77)$ suggesting a slight association. Interestingly, results were quite heterogeneous and stronger associations were found with more recently published studies.[43] The pooled estimate for the association between "Intermittent Sun Exposure" and melanoma was more convincing at a RR of $1.61(1.31,1.99)$.[43] While there is a significant amount of heterogeneity in the studies used for the pooled RR, it was felt this was most likely secondary to the many differing definitions for "intermittent sun exposure." [43] When two studies that included CMM in children which were previously removed from analysis were added back into the calculation of RR, the estimate did not change much and only increased to $1.62(1.31,1.99)$. [43] Surprisingly, the RR for "chronic UV exposure" and melanoma was slightly protective, although not significantly ( $R R=0.95$; CI: $0.87,1.04)$. Finally, this meta-analysis also reviewed the exposure of sunburn history, which demonstrated a RR of $2.03(1.73,2.37)$. Within this group, it was found that studies where the population was from a latitude higher than 50 had a higher RR, reported as $2.54(1.99,3.24)$. Those studies whose population 
resided at a lower latitude still demonstrated a statistically significant RR of 1.91 (1.58, 2.31).[43] Unfortunately, given the rare occurrence of melanoma in absolute terms, it is difficult to perform a prospective study, and as such, it is exceedingly difficult to characterize the pattern of sun exposure that places patients at greatest risk through these retrospective studies.[43] The possibility of recall bias is important in these retrospective studies, and prior investigations have found that certain exposures questioned, such as number of sunburns, is free from recall bias.[44] However, tanning ability does seem to be affected by recall bias.[45] Further studies in twins have attempted to further detail the effect of recall bias, which found the opposite to be true in regard to tanning ability (not affected by recall bias) and sunburn history (affected by recall bias).[46] These discordant data indicate further study is required into the effect that recall bias may have with these retrospectively conducted studies on CMM.

The pathophysiology of melanoma development in concert with UV radiation has been proposed in prior studies. A mutated p53 tumor suppressor gene has been reported in many cases of melanoma, and UV radiation has been studied as a potential mutagen for the p53 gene.[47] Other associations between melanoma and high altitudes where higher UV fluences are found, and with certain body sites (legs in women, the back in men) with higher UV exposure rates have been reported, further demonstrating a possible causal relationship. [48-50]

The timing of the sun exposure may play a role as well. A study found that those born in Northern Europe but who moved to Australia, where the UV radiation environment is higher, had a lower rate of melanoma if the move occurred after the age of 10.[51] Alternatively, another study found that melanoma risk doubled with 5 sunburns, regardless of if these occurred prior to or after the age of 15.[52]

While it is safe to conclude that excessive exposure is the major environmental risk factor for melanoma, patterns of exposure and the interplay between sunlight and skin pigmentation makes the analysis more complicated and deserve further study.

Indoor Tanning/Artificial Sunlamps-As previously indicated, indoor tanning is thought to be a potential contributor to the increasing incidence of CMM among young women.[5] A large case-control study from the Nurses Health Study published in 2006 found an OR for "ever" versus "never" usage of tanning booths and melanoma to be 2.06 $(1.30,3.26) .[53]$ When stratified, another study by Lazovich et al demonstrated an increased risk of melanoma diagnosis with increasing years, hours, and sessions of tanning behavior. [54] A more recent review by the Gandini group demonstrates that "ever" usage status of tanning booths before the age of 30 portends an increase of melanoma risk by 75 percent. [55]

A separate review from 2011 by the Cust group found that ever users of sunbeds were at an increased risk of CMM than never uses with an OR of $1.41(1.01,1.96)$. When further subdivided, those that had used sunbeds more than 10 times had a higher OR of 2.01 (1.22, 3.31).[56] A subgroup analysis further found that earlier age of first sunbed use also was increasingly associated with CMM diagnosis.[56]

Most recently, a meta-analysis by Boniol et al reviewed 27 articles having to do with artificial UV exposure and association with CMM. Case-control, cross-sectional, and cohort studies were included, however case reports were excluded. They report an overall summary RR of $1.20(1.08,1.34)$ for ever use of sunbeds compared to those without this exposure on association with CMM.[57] When the population is further stratified to those less than 35 years of age, the summary RR is reported as a $1.87(1.41,2.48)$.[57] 
Organ Transplant Recipients-Melanoma, being an immune-responsive tumor, unsurprisingly behaves differently in the immunocompromised host. Patients who are recipients of organ transplants remain on immunosuppression for long term to prevent graft rejection. As such, there are two groups of transplant patients for whom we must be mindful regarding their melanoma diagnosis: Those that were transplanted after a prior diagnosis of malignant melanoma, and those that develop a melanoma after transplantation. A study from 2011 demonstrated that when compared with expected survival rates for melanoma derived from the Surveillance, Epidemiology, and End Results (SEER) database, those with a history of transplantation had a poorer prognosis regardless of Breslow thickness or Clark level.[58]

However, aside from prognosis after diagnosis of CMM, one should also be concerned for the potentially increased risk of CMM after organ transplant. A review of non-infection related malignancies among those with organ transplants reported 381 cases observed in their cohort to the $\sim 180$ expected based on published rates in the general public applied to the registry population. The standardized incidence ratio (SIR) was reported as $2.38(2.14$, 2.63) in this population, indicating an increased risk of CMM.[59]

Non-steroidal anti-inflammatory drug use-A recent study explored the possible protective effects of non-steroidal anti-inflammatory drug (NSAID) intake on skin cancer risk. All skin cancer cases were recorded for northern Denmark, and controls were taken from the population matching 10 controls for each case. Exposure was defined as ever use of NSAIDs (>2 prescriptions) versus controls which were defined as never use of NSAIDs ( 2 prescriptions). The incident rate ratio (IRR) for these group and CMM was reported as 0.87 $(0.80,0.95)$, indicating a possible protective effect on CMM.[60]

TNF- $\boldsymbol{\alpha}$ inhibitor use-A study from the gastroenterology literature also highlighted the potential risk of CMM diagnosis after usage of TNF- $a$ inhibitors in a population of inflammatory bowel disease (IBD) patients.[61] In a nested case-control study, use of TNF$a$ inhibitors in the setting of IBD showed an odds ratio of $1.88(1.08,3.29)$ when compared to non-use. However, when subdivided by length of therapy, this association was not seen when TNF- $a$ inhibitors were used for fewer than 120 days. When the opposite is investigated, "long term use" of TNF- $a$ inhibitors saw an OR of $3.93(182,8.50)$ when compared to "non-long term use" of TNF- $a$ inhibitors for CMM diagnosis.[61]

\section{SCREENING AND PREVENTION}

Most experts agree that prevention is a key component to decreasing melanoma mortality. While primary prevention revolves around sun-protection in hopes of decreasing the incidence of melanoma development, one can also consider the importance of secondary prevention, the hope of diagnosing melanoma early enough to mitigate the risk of mortality from the disease. The most obvious example is our frequent surveillance of those we deem at high risk, however it would be prudent to explore whether this action taken by almost all dermatologists, actually diminishes mortality. A large scale skin cancer screening program of more than 360,000 residents in the German Federal State of Schleswig-Holstein from 7/1/03-6/30/04 utilized both dermatologists and non-dermatologists. Incidence rose by $30 \%$ in the screened area relative to the rest of Germany and $50 \%$ of all melanomas reported to the Schleswig-Holstein registry arose from the formal screening program. [62] Most notably, mortality-rates from CMM in Schleswig-Holstein decreased by 50 percent compared with Denmark to the north and all other areas of Germany. Overall, there was a decrease of $7.4 \%$ per year (7.5 percent decrease in men, 7.1 percent in women), which was not seen in other areas in Germany and Denmark.[63] While these results need to be interpreted cautiously, as the authors also indicate there are other factors at play such as a 
heightened awareness, this certainly raises important implications for the possibility of decreasing CMM mortality with skin cancer screening programs. Because of the success of the Schleswig-Holstein study, a national screening program is currently taking place in Germany-more than 20 million residents have been screened and 77\% of German physicians have taken part in an 8-hour training program (Dr. Eckhard Breitbart; personal communication, August 15, 2012).

While secondary prevention is important, an even more attractive option may actually be primary prevention. The ability to completely prevent a new case of melanoma is an attractive proposition. As such, the possibility of chemoprevention has been raised. A recent study from Cancer in 2012 investigated the possibility of an association between statin usage and a lower risk of melanoma based on data that suggested simvastatin may be able to decrease the melanoma cell's ability to adhere to laminin and collagen type IV.[64] Unfortunately, the data from the study did not support the possible decrease of melanoma risk from statin usage, despite prior invitro data supporting a salutary effect.[64] More exciting are the data presented above regarding the possible protective effects of NSAIDs on CMM risk.[60]

In terms of sun protection with sunscreens for prevention of CMM, a study that was started in 1992 randomized 1621 participants to either daily or discretionary application of broadspectrum sunscreen to the head and neck revealed that while statistical significance was not seen, there is certainly a suggestion of a trend toward protection against CMM diagnosis at any body site in the daily application of sunscreen group. The overall HR was marginally significant $0.50(0.24,1.02)$ while the decrease in invasive melanomas was substantial ( $\mathrm{HR}=0.27,0.08$ to 0.97 ).[65] With the results of this randomized trial, it is difficult to ignore these data in our daily counseling of patients for improved sun protection to prevent not only NMSC, but also CMM.

Future studies may show more convincing data to the contrary, however currently, protection and avoidance from UV remains the only reliable type of primary prevention for CMM.

\section{Conclusion}

Full control of the "melanoma epidemic" will require efforts, and successes, in both early detection/prevention and disease-mitigating drugs. New trends have emerged (e.g. increasing incidence among young women), novel associations are being explored (e.g. Parkinson's disease and melanoma), population-based screening studies have been conducted and predisposing alleles have been uncovered through GWAS. It is certainly an exciting time in the field of melanoma epidemiology.

\section{References}

Papers of particular interest, published recently, have been highlighted as:

** Of major importance

* Of importance

1. Society AC., editor. Cancer Facts and Figures. Edition Atlanta, GA: 2012.

2. Shoo BA, Kashani-Sabet M. Melanoma arising in African-, Asian-, Latino- and Native-American populations. Semin Cutan Med Surg. 2009; 28:96-102. [PubMed: 19608060]

3. Linos E, Swetter SM, Cockburn MG, et al. Increasing burden of melanoma in the United States. J Invest Dermatol. 2009; 129:1666-1674. [PubMed: 19131946] 
4. Purdue MP, Freeman LE, Anderson WF, Tucker MA. Recent trends in incidence of cutaneous melanoma among US Caucasian young adults. J Invest Dermatol. 2008; 128:2905-2908. [PubMed: 18615112]

5. Reed KB, Brewer JD, Lohse CM, et al. Increasing incidence of melanoma among young adults: an epidemiological study in Olmsted County, Minnesota. Mayo Clin Proc. 2012; 87:328-334. [PubMed: 22469345]

6. Tucker MA. Melanoma epidemiology. Hematol Oncol Clin North Am. 2009; 23:383-395. vii. [PubMed: 19464592]

7. Wolchok J. How recent advances in immunotherapy are changing the standard of care for patients with metastatic melanoma. Ann Oncol. 2012; 23(Suppl 8):viii15-viii21. [PubMed: 22918923]

8. Seidler AM, Pennie ML, Veledar E, et al. Economic burden of melanoma in the elderly population: population-based analysis of the Surveillance, Epidemiology, and End Results (SEER)--Medicare data. Arch Dermatol. 2010; 146:249-256. [PubMed: 20231494]

9. Tsao H, Rogers GS, Sober AJ. An estimate of the annual direct cost of treating cutaneous melanoma. J Am Acad Dermatol. 1998; 38:669-680. [PubMed: 9591809]

10. Chu EY, Wanat KA, Miller CJ, et al. Diverse cutaneous side effects associated with BRAF inhibitor therapy: A clinicopathologic study. J Am Acad Dermatol. 2012

11. Gandini S, Sera F, Cattaruzza MS, et al. Meta-analysis of risk factors for cutaneous melanoma: I. Common and atypical naevi. Eur J Cancer. 2005; 41:28-44. [PubMed: 15617989]

12. Olsen CM, Carroll HJ, Whiteman DC. Estimating the attributable fraction for cancer: A metaanalysis of nevi and melanoma. Cancer Prev Res (Phila). 2010; 3:233-245. [PubMed: 20086181]

13. Gandini S, Sera F, Cattaruzza MS, et al. Meta-analysis of risk factors for cutaneous melanoma: III. Family history, actinic damage and phenotypic factors. Eur J Cancer. 2005; 41:2040-2059. [PubMed: 16125929]

14. Wheless L, Black J, Alberg AJ. Nonmelanoma skin cancer and the risk of second primary cancers: a systematic review. Cancer Epidemiol Biomarkers Prev. 2010; 19:1686-1695. [PubMed: 20570907]

15. Pappo AS, Armstrong GT, Liu W, et al. Melanoma as a subsequent neoplasm in adult survivors of childhood cancer: A report from the childhood cancer survivor study. Pediatr Blood Cancer. 2012

16. Bajaj A, Driver JA, Schernhammer ES. Parkinson's disease and cancer risk: a systematic review and meta-analysis. Cancer Causes Control. 2010; 21:697-707. [PubMed: 20054708]

17. Liu R, Gao X, Lu Y, Chen H. Meta-analysis of the relationship between Parkinson disease and melanoma. Neurology. 2011; 76:2002-2009. [PubMed: 21646627]

18. Gao X, Simon KC, Han J, et al. Genetic determinants of hair color and Parkinson's disease risk. Ann Neurol. 2009; 65:76-82. [PubMed: 19194882]

19. Gandini S, Iodice S, Koomen E, et al. Hormonal and reproductive factors in relation to melanoma in women: current review and meta-analysis. Eur J Cancer. 2011; 47:2607-2617. [PubMed: 21620689]

20. Karagas MR, Stukel TA, Dykes J, et al. A pooled analysis of 10 case-control studies of melanoma and oral contraceptive use. Br J Cancer. 2002; 86:1085-1092. [PubMed: 11953854]

21. Randerson-Moor JA, Taylor JC, Elliott F, et al. Vitamin D receptor gene polymorphisms, serum 25-hydroxyvitamin D levels, and melanoma: UK case-control comparisons and a meta-analysis of published VDR data. Eur J Cancer. 2009; 45:3271-3281. [PubMed: 19615888]

22. Asgari MM, Maruti SS, Kushi LH, White E. A cohort study of vitamin D intake and melanoma risk. J Invest Dermatol. 2009; 129:1675-1680. [PubMed: 19194478]

23*. Udayakumar D, Tsao H. Melanoma genetics: an update on risk-associated genes. Hematol Oncol Clin North Am. 2009; 23:415-429. vii. [PubMed: 19464594] Authors review genes of variable risk implicated in CMM, most notably CDKN2A.

24. Njauw CN, Kim I, Piris A, et al. Germline BAP1 inactivation is preferentially associated with metastatic ocular melanoma and cutaneous-ocular melanoma families. PLoS One. 2012; 7:e35295. [PubMed: 22545102]

25. Raimondi S, Sera F, Gandini S, et al. MC1R variants, melanoma and red hair color phenotype: a meta-analysis. Int J Cancer. 2008; 122:2753-2760. [PubMed: 18366057] 
26. Palmer JS, Duffy DL, Box NF, et al. Melanocortin-1 receptor polymorphisms and risk of melanoma: is the association explained solely by pigmentation phenotype? Am J Hum Genet. 2000; 66:176-186. [PubMed: 10631149]

27. Matichard E, Verpillat P, Meziani R, et al. Melanocortin 1 receptor (MC1R) gene variants may increase the risk of melanoma in France independently of clinical risk factors and UV exposure. $\mathrm{J}$ Med Genet. 2004; 41:e13. [PubMed: 14757863]

28. Stratigos AJ, Dimisianos G, Nikolaou V, et al. Melanocortin receptor-1 gene polymorphisms and the risk of cutaneous melanoma in a low-risk southern European population. J Invest Dermatol. 2006; 126:1842-1849. [PubMed: 16601669]

29. Williams PF, Olsen CM, Hayward NK, Whiteman DC. Melanocortin 1 receptor and risk of cutaneous melanoma: a meta-analysis and estimates of population burden. Int J Cancer. 2011; 129:1730-1740. [PubMed: 21128237]

$30 * *$. Chatzinasiou F, Lill CM, Kypreou K, et al. Comprehensive field synopsis and systematic metaanalyses of genetic association studies in cutaneous melanoma. J Natl Cancer Inst. 2011; 103:1227-1235. [PubMed: 21693730] A review and meta-analysis of genetic factors associated with CMM. This review also contains data from GWAS papers to review SNP associations with CMM.

31. Hayward NK. Genetics of melanoma predisposition. Oncogene. 2003; 22:3053-3062. [PubMed: 12789280]

32. Box NF, Duffy DL, Chen W, et al. MC1R genotype modifies risk of melanoma in families segregating CDKN2A mutations. Am J Hum Genet. 2001; 69:765-773. [PubMed: 11500805]

33. Fargnoli MC, Gandini S, Peris K, et al. MC1R variants increase melanoma risk in families with CDKN2A mutations: a meta-analysis. Eur J Cancer. 2010; 46:1413-1420. [PubMed: 20189796]

34. Brown KM, Macgregor S, Montgomery GW, et al. Common sequence variants on 20q11.22 confer melanoma susceptibility. Nat Genet. 2008; 40:838-840. [PubMed: 18488026]

35. Bishop DT, Demenais F, Iles MM, et al. Genome-wide association study identifies three loci associated with melanoma risk. Nat Genet. 2009; 41:920-925. [PubMed: 19578364]

36. Duffy DL, Zhao ZZ, Sturm RA, et al. Multiple pigmentation gene polymorphisms account for a substantial proportion of risk of cutaneous malignant melanoma. J Invest Dermatol. 2010; 130:520-528. [PubMed: 19710684]

37. Falchi M, Bataille V, Hayward NK, et al. Genome-wide association study identifies variants at 9p21 and 22q13 associated with development of cutaneous nevi. Nat Genet. 2009; 41:915-919. [PubMed: 19578365]

38. Duffy DL, Iles MM, Glass D, et al. IRF4 variants have age-specific effects on nevus count and predispose to melanoma. Am J Hum Genet. 2010; 87:6-16. [PubMed: 20602913]

39. Amos CI, Wang LE, Lee JE, et al. Genome-wide association study identifies novel loci predisposing to cutaneous melanoma. Hum Mol Genet. 2011; 20:5012-5023. [PubMed: 21926416]

40. Barrett JH, Iles MM, Harland M, et al. Genome-wide association study identifies three new melanoma susceptibility loci. Nat Genet. 2011; 43:1108-1113. [PubMed: 21983787]

41. Macgregor S, Montgomery GW, Liu JZ, et al. Genome-wide association study identifies a new melanoma susceptibility locus at 1q21.3. Nat Genet. 2011; 43:1114-1118. [PubMed: 21983785]

42. Law MH, Montgomery GW, Brown KM, et al. Meta-analysis combining new and existing data sets confirms that the TERT-CLPTM1L locus influences melanoma risk. J Invest Dermatol. 2012; 132:485-487. [PubMed: 21993562]

43. Gandini S, Sera F, Cattaruzza MS, et al. Meta-analysis of risk factors for cutaneous melanoma: II. Sun exposure. Eur J Cancer. 2005; 41:45-60. [PubMed: 15617990]

44. Berwick M, Chen YT. Reliability of reported sunburn history in a case-control study of cutaneous malignant melanoma. Am J Epidemiol. 1995; 141:1033-1037. [PubMed: 7771439]

45. Weinstock MA, Colditz GA, Willett WC, et al. Recall (report) bias and reliability in the retrospective assessment of melanoma risk. Am J Epidemiol. 1991; 133:240-245. [PubMed: 2000841]

46. Cockburn M, Hamilton A, Mack T. Recall bias in self-reported melanoma risk factors. Am J Epidemiol. 2001; 153:1021-1026. [PubMed: 11384959] 
47. Ouhtit A, Nakazawa H, Armstrong BK, et al. UV-radiation-specific p53 mutation frequency in normal skin as a predictor of risk of basal cell carcinoma. J Natl Cancer Inst. 1998; 90:523-531. [PubMed: 9539248]

48. Rigel DS, Rigel EG, Rigel AC. Effects of altitude and latitude on ambient UVB radiation. J Am Acad Dermatol. 1999; 40:114-116. [PubMed: 9922027]

49. Bulliard JL. Site-specific risk of cutaneous malignant melanoma and pattern of sun exposure in New Zealand. Int J Cancer. 2000; 85:627-632. [PubMed: 10699940]

50. Parisi AV, Kimlin MG, Lester R, Turnbull D. Lower body anatomical distribution of solar ultraviolet radiation on the human form in standing and sitting postures. J Photochem Photobiol B. 2003; 69:1-6. [PubMed: 12547490]

51. Holman CD, Armstrong BK. Cutaneous malignant melanoma and indicators of total accumulated exposure to the sun: an analysis separating histogenetic types. J Natl Cancer Inst. 1984; 73:75-82. [PubMed: 6588237]

52. Pfahlberg A, Kolmel KF, Gefeller O. Timing of excessive ultraviolet radiation and melanoma: epidemiology does not support the existence of a critical period of high susceptibility to solar ultraviolet radiation-induced melanoma. Br J Dermatol. 2001; 144:471-475. [PubMed: 11260001]

53. Han J, Colditz GA, Hunter DJ. Risk factors for skin cancers: a nested case-control study within the Nurses' Health Study. Int J Epidemiol. 2006; 35:1514-1521. [PubMed: 16943234]

54. Lazovich D, Vogel RI, Berwick M, et al. Indoor tanning and risk of melanoma: a case-control study in a highly exposed population. Cancer Epidemiol Biomarkers Prev. 2010; 19:1557-1568. [PubMed: 20507845]

55**. Gandini S, Autier P, Boniol M. Reviews on sun exposure and artificial light and melanoma. Prog Biophys Mol Biol. 2011; 107:362-366. [PubMed: 21958910] A recent review article covering risk of UV exposure and CMM diagnosis. Particular attention is paid to tanning booth usage and subsequent risk of CMM.

56. Cust AE, Armstrong BK, Goumas C, et al. Sunbed use during adolescence and early adulthood is associated with increased risk of early-onset melanoma. Int J Cancer. 2011; 128:2425-2435. [PubMed: 20669232]

57*. Boniol M, Autier P, Boyle P, Gandini S. Cutaneous melanoma attributable to sunbed use: systematic review and meta-analysis. BMJ. 2012; 345:e4757. [PubMed: 22833605] Authors perform a meta-analysis to specifically explore the risk imparted for CMM from tanning booth usage.

58. Brewer JD, Christenson LJ, Weaver AL, et al. Malignant melanoma in solid transplant recipients: collection of database cases and comparison with surveillance, epidemiology, and end results data for outcome analysis. Arch Dermatol. 2011; 147:790-796. [PubMed: 21768478]

59. Engels EA, Pfeiffer RM, Fraumeni JF Jr. et al. Spectrum of cancer risk among US solid organ transplant recipients. JAMA. 2011; 306:1891-1901. [PubMed: 22045767]

60. Johannesdottir SA, Chang ET, Mehnert F, et al. Nonsteroidal anti-inflammatory drugs and the risk of skin cancer: A population-based case-control study. Cancer. 2012; 118:4768-4776. [PubMed: 22644960]

61. Long MD, Martin CF, Pipkin CA, et al. Risk of melanoma and nonmelanoma skin cancer among patients with inflammatory bowel disease. Gastroenterology. 143:390-399. e391. [PubMed: 22584081]

62. Breitbart EW, Waldmann A, Nolte S, et al. Systematic skin cancer screening in Northern Germany. J Am Acad Dermatol. 2012; 66:201-211. [PubMed: 22074699]

63*. Katalinic A, Waldmann A, Weinstock MA, et al. Does skin cancer screening save lives?: An observational study comparing trends in melanoma mortality in regions with and without screening. Cancer. 2012; 118:5395-5402. [PubMed: 22517033] Data presented by authors support the idea that systematic screening can decrease CMM mortality.

64. Pasco S, Brassart B, Ramont L, et al. Control of melanoma cell invasion by type IV collagen. Cancer Detect Prev. 2005; 29:260-266. [PubMed: 15936594]

65*. Green AC, Williams GM, Logan V, Strutton GM. Reduced melanoma after regular sunscreen use: randomized trial follow-up. J Clin Oncol. 2011; 29:257-263. [PubMed: 21135266] Authors demonstrate decreased incidence of CMM with sunscreen usage for prevention 
Table One

Summary of Relative Risks and Odds Ratios ${ }^{* *}$

\begin{tabular}{|c|c|c|c|}
\hline Risk Factor/Characteristic & Comparison Group & $\begin{array}{c}\text { Summary } \\
\text { Statistic } \\
\text { (RR, OR, } \\
\text { or HR) }\end{array}$ & $\begin{array}{c}\text { Confidence } \\
\text { Interval }\end{array}$ \\
\hline \multicolumn{4}{|l|}{ Known Physiologic Risk } \\
\hline \multicolumn{4}{|l|}{ Factors } \\
\hline \multicolumn{4}{|l|}{ Nevi } \\
\hline 16-40 total common nevi & $\begin{array}{l}0-15 \text { total common } \\
\text { nevi }\end{array}$ & 1.47 & $1.36-1.59$ \\
\hline 41-60 total common nevi & & 2.24 & $1.90-2.64$ \\
\hline $61-80$ total common nevi & & 3.26 & $2.55-4.15$ \\
\hline $81-100$ total common nevi & & 4.74 & $3.44-6.53$ \\
\hline $101-120$ total common nevi & & 6.89 & $4.63-10.25$ \\
\hline 1-5 arm common nevi & 0 arm common nevi & 1.44 & $1.29-1.60$ \\
\hline 5-10 arm common nevi & & 2.48 & $1.90-3.23$ \\
\hline 11-15 arm common nevi & & 4.82 & $3.05-7.62$ \\
\hline 1 atypical nevus history & 0 atypical nevi history & 1.45 & $1.31-1.60$ \\
\hline 2 atypical nevi history & & 2.10 & $1.71-2.54$ \\
\hline 3 atypical nevi history & & 3.03 & $2.23-4.06$ \\
\hline 4 atypical nevi history & & 4.39 & $2.91-6.47$ \\
\hline 5 atypical nevi history & & 6.36 & $3.80-10.33$ \\
\hline \multicolumn{4}{|l|}{ Eye Color } \\
\hline Blue & Dark & 1.47 & $1.28-1.69$ \\
\hline Green & & 1.61 & $1.06-2.45$ \\
\hline Hazel & & 1.52 & $1.26-1.83$ \\
\hline Above grouped as "fair" & & 1.62 & $1.44-1.81$ \\
\hline \multicolumn{4}{|l|}{ Hair Color } \\
\hline Red & Dark & 3.64 & $2.56-5.37$ \\
\hline Blond & & 1.96 & $1.41-2.74$ \\
\hline Light brown & & 1.62 & $1.11-2.34$ \\
\hline Above grouped as "light" & & 1.78 & $1.63-1.95$ \\
\hline \multicolumn{4}{|l|}{ Family History } \\
\hline Positive family history & $\begin{array}{l}\text { Negative family } \\
\text { history }\end{array}$ & 1.74 & $1.41-2.14$ \\
\hline \multicolumn{4}{|l|}{ Personal history of NMSC } \\
\hline $\begin{array}{l}\text { Any Personal history of } \\
\text { NMSC }\end{array}$ & $\begin{array}{l}\text { No personal history of } \\
\text { NMSC }\end{array}$ & 2.74 & $2.49-3.02$ \\
\hline Personal history of SCC & & 2.84 & $2.45-3.29$ \\
\hline Personal history of $\mathrm{BCC}$ & & 2.75 & $2.39-3.16$ \\
\hline \multicolumn{4}{|l|}{ Parkinson's Disease (PD) } \\
\hline Personal history of PD & $\begin{array}{l}\text { No personal history of } \\
\text { PD }\end{array}$ & $\begin{array}{l}* 1.56 \\
2.11\end{array}$ & $\begin{array}{l}* 1.27-1.91 \\
1.26-3.54\end{array}$ \\
\hline
\end{tabular}

Vitamin D Receptor SNPs 


\begin{tabular}{|c|c|c|c|}
\hline Risk Factor/Characteristic & Comparison Group & $\begin{array}{c}\text { Summary } \\
\text { Statistic } \\
\text { (RR, OR, } \\
\text { or HR) }\end{array}$ & $\begin{array}{c}\text { Confidence } \\
\text { Interval }\end{array}$ \\
\hline Presence FokI T allele & $\begin{array}{l}\text { Absence of FokI T } \\
\text { allele }\end{array}$ & 1.19 & $1.05-1.35$ \\
\hline Presence of BsmI A allele & $\begin{array}{l}\text { Absence of BsmI A } \\
\text { allele }\end{array}$ & 0.81 & $0.72-0.92$ \\
\hline \multicolumn{4}{|l|}{ Genetic Factors } \\
\hline$M C 1 R$ variants in RHC group & Wildtype $M C 1 R$ & 2.44 & $1.72-3.45$ \\
\hline $\begin{array}{l}M C 1 R \text { variants in NRHC } \\
\text { group }\end{array}$ & & 1.29 & $1.10-1.51$ \\
\hline \multicolumn{4}{|l|}{ Exogenous/Iatrogenic Factors } \\
\hline \multicolumn{4}{|l|}{ Sun Exposure } \\
\hline $\begin{array}{l}\text { High amount of Total Sun } \\
\text { Exposure }\end{array}$ & $\begin{array}{l}\text { Low amount of Total } \\
\text { Sun Exposure }\end{array}$ & 1.34 & $1.02-1.77$ \\
\hline $\begin{array}{l}\text { High amount of Intermittent } \\
\text { Sun Exposure }\end{array}$ & $\begin{array}{l}\text { Low amount of } \\
\text { Intermittent Sun } \\
\text { Exposure }\end{array}$ & 1.61 & $1.31-1.99$ \\
\hline $\begin{array}{l}\text { High amount of chronic UV } \\
\text { exposure }\end{array}$ & $\begin{array}{l}\text { Low amount of } \\
\text { chronic UV exposure }\end{array}$ & 0.95 & $0.87-1.04$ \\
\hline Strong history of sunburn & $\begin{array}{c}\text { Weak history of } \\
\text { sunburn }\end{array}$ & 2.03 & $1.73-2.37$ \\
\hline \multicolumn{4}{|l|}{ Indoor tanning/Sunlamps } \\
\hline Ever use of tanning booth & $\begin{array}{l}\text { Never use of tanning } \\
\text { booth }\end{array}$ & $\begin{array}{l}*^{2} .06 \\
1.20\end{array}$ & $\begin{array}{l}* 1.30-3.26 \\
1.08-1.34\end{array}$ \\
\hline \multicolumn{4}{|l|}{ Organ Transplant } \\
\hline History of organ transplant & $\begin{array}{l}\text { No history of organ } \\
\text { transplant }\end{array}$ & 2.38 & $2.14-2.63$ \\
\hline \multicolumn{4}{|l|}{ NSAID Usage } \\
\hline O Ever use of NSAIDs & Never use of NSAIDs & 0.87 & $0.80-0.95$ \\
\hline
\end{tabular}

Abbreviations: RR: relative risk, OR: odds ratio, HR: hazard ratio, NMSC: nonmelanoma skin cancer, SCC: squamous cell carcinoma, BCC: basal cell carcinoma, SNP: single nucleotide polymorphism, RHC: red hair color, NRHC: non-red hair color, NSAID: nonsteroidal antiinflammatory drug

Multiple articles with different summary statistics.

Each study adjusted for different factors. Please see text and original articles for further details. 